\title{
A atualidade de Guerreiro Ramos: desenvolvimento, racismo e colonialidade no Brasil de 2021
}

The topicality of Guerreiro Ramos: development, racism and coloniality in today's Brazil

\section{Fábio Borges* Luiza Maria Martins*}

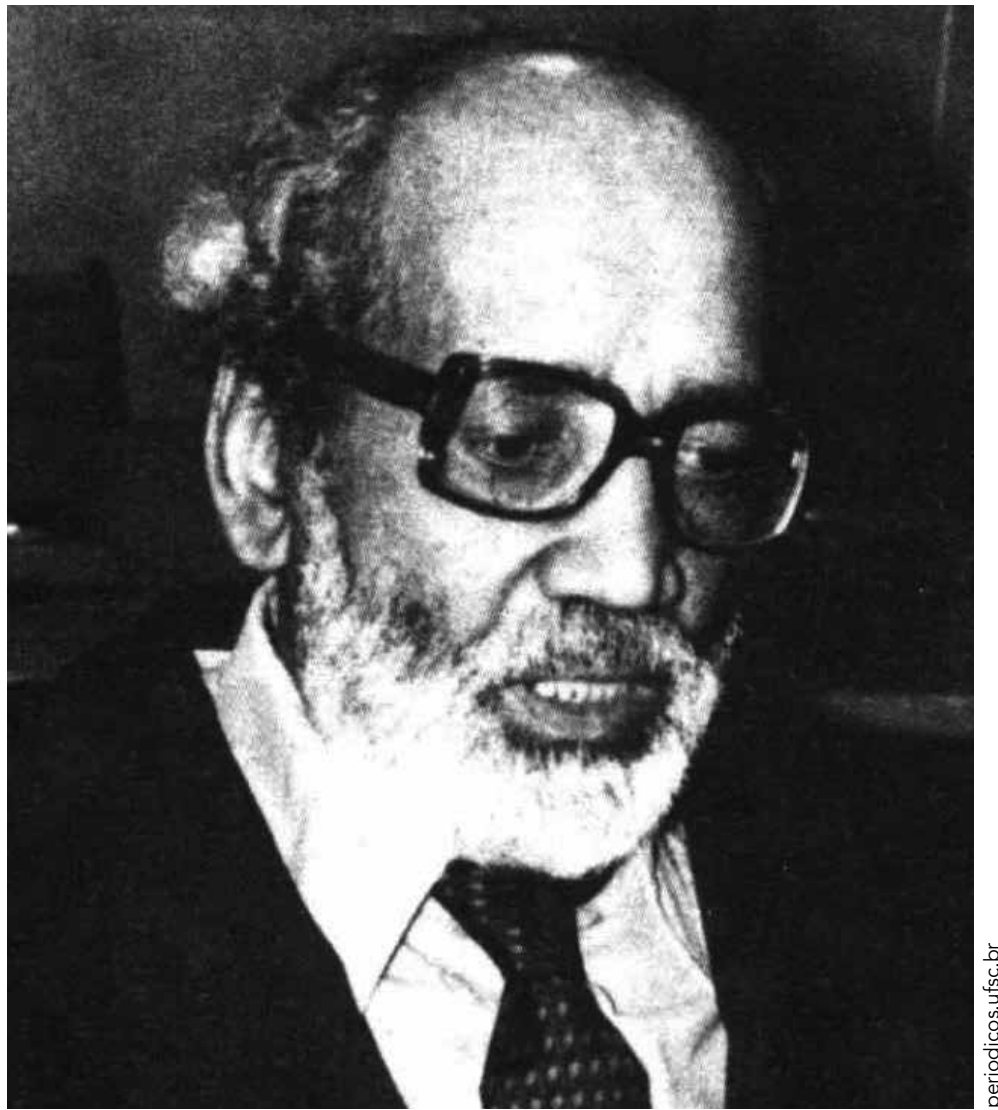

Alberto Guerreiro Ramos (1915-1982), sociólogo e político brasileiro 


\section{RESUMO}

O Brasil em 202I passa por um período muito crítico, com a ascensão de um grupo de uma direita bruta, representada na figura do presidente Jair Bolsonaro, que em tese implementaria políticas neoliberais lideradas pelo ministro Paulo Guedes. Ao mesmo tempo, desde 2020 o país vem enfrentando uma de suas piores crises sanitárias e econômicas, com um número lamentável de vítimas da covid-ı. Também são anos marcados por muita violência relacionada ao racismo, com uma intensificação de assassinatos praticados pelo aparato policial, especialmente da população negra, no Brasil. Diante de tal quadro, nada nos parece mais pertinente que recuperar o pensamento do sociólogo Guerreiro Ramos para entender o Brasil atual, já que foi um autor que de forma original aprofundou os temas do desenvolvimento, do racismo e da colonialidade. A hipótese central é que a situação social, econômica e política brasileira carece de uma análise profunda, crítica e original na busca pela transformação dessa situação trágica por que o país passa, sendo Guerreiro Ramos talvez uma referência pouco trabalhada ainda, nesse sentido.

Palavras-chave: Guerreiro Ramos. Desenvolvimento. Racismo. Colonialidade. Atualidade.

\section{ABSTRACT}

In 202I Brazil is going through a very critical period, with the rise of a extreme right group, represented by president Jair Bolsonaro, who in theory would implement neoliberal policies led by minister Paulo Guedes. At the same time, since 2020 the country has been facing one of its worst health and economic crises, with a regrettable number of victims of covid-I9. It is also a year marked by violence related to racism, with an intensification of murders committed by the police apparatus, especially of the black population in Brazil. Given this situation, nothing seems more pertinent than recovering the ideas of sociologist Guerreiro Ramos in order to understand today's Brazil, since he was an author who in an original way deepened the themes of development, racism and coloniality. The central hypothesis is that the Brazilian social, economic and political situation lacks a deep, critical and original analysis in the search for the transformation of this tragic situation that the country is going through, with Guerreiro Ramos being a reference that has been little employ on this regard.

Keywords: Guerreiro Ramos. Development. Racism. Coloniality. Contemporaneity. 


\section{INTRODUCÃ̃O}

O Brasil em 202I passa por um período muito crítico, com a ascensão de um grupo de uma direita bruta, representada na figura do presidente Jair Bolsonaro, que em tese implementaria políticas neoliberais lideradas pelo ministro Paulo Guedes.

Paulo Guedes é ministro da Economia desde 20I8, ano em que o ministério foi criado. Tem graduação em Economia pela Universidade Federal de Minas Gerais (UFMG), passagem na pós-graduação na Fundação Getúlio Vargas carioca e mestrado e doutorado pela Universidade de Chicago, sem dúvida um defensor fervoroso da crença neoliberal. Atuou como docente na FGV, na Pontifícia Universidade Católica do Rio de Janeiro (PUC-Rio) e no Ibmec durante as décadas de I980 e I990. As consultas sobre sua formação foram feitas a partir de fontes secundárias, visto que seu currículo acadêmico não é registrado na Plataforma Lattes. A convite de Jorge Selume, diretor de orçamento na ditadura chilena de Augusto Pinochet, e também colega de Guedes na Universidade de Chicago, o atual ministro acompanhou, como docente na Universidade do Chile, as reformas econômicas implementadas naquele país durante o período autoritário. Não à toa, ao lado de Bolsonaro, defendeu explicitamente a implementação das reformas de Pinochet no Brasil — privatizações, reformas tributárias e previdenciárias. Na política brasileira, teve visibilidade apenas com Bolsonaro. No final do século XX, defendeu o Plano Real e estruturou o projeto econômico de Guilherme Afif Domingos quando este concorreu à Presidência em 1989. Atuou mais fortemente no setor privado, sendo um dos fundadores do banco de investimentos de risco Pactual e do think tank Instituto Millenium.

Ao mesmo tempo, desde 2020 o país vem enfrentando uma de suas piores crises sanitárias e econômicas, com um número lamentável de vítimas da covid-I9. Os números da Organização Mundial da Saúde são assustadores: são 30.434 novos casos diários, totalizando I6.545.554 casos confirmados e 462.79I mortes por covid-I9, enquanto a vacinação caminha a lentos passos, com apenas 60.0I7.445 vacinados (menos de $28 \%$ da população brasileira) até junho de 202I.

Também é um ano marcado por muita violência relacionada ao racismo, com uma intensificação de assassinatos praticados pelo aparato policial no Brasil, especialmente da população negra local. Apesar da ação de descumprimento de preceito fundamental (ADPF) no 635, determinada pelo Supremo Tribunal Federal, que impedia as operações em favelas cariocas durante a pandemia de covid-ı, a chacina na favela do Jacarezinho no Rio de Janeiro é um exemplo da excepcionalidade que as pessoas negras vivem no Brasil. Com 28 mortes devidas à ação da Polícia Civil em 6 de maio de 202I, a chacina é tida como a segunda pior da história do estado - I3 dos mortos, na maioria negros, nem sequer estavam sendo investigados.

Diante de tal quadro, nada nos parece mais pertinente que recuperar o pensamento do sociólogo Guerreiro Ramos para entender o Brasil atual, já que foi um autor que de forma original aprofundou os temas do desenvolvimento, do racismo e da colonialidade. A hipótese central é que a situação social, econômica e política brasileira 


\section{Foi um ator político nacional e dentro da própria academia: no espaço de homens brancos, era firme e polêmico, com ideias contra- hegemônicas de estruturar um pensamento sociológico no Brasil e para o Brasil}

carece de uma análise profunda, crítica e original na busca pela transformação dessa situação trágica por que o país passa, sendo Guerreiro Ramos talvez uma referência pouco trabalhada ainda, nesse sentido.

\section{O DRAMA DE SER DOIS}

"Posto entre os dois mundos conflitantes - o do negro, que ele rechaça, e o do branco, que o rejeita -, o mulato se humaniza no drama de ser dois, que é o de ser ninguém." (RAMOS apud RIBEIRO, 20I4, p. I92)

O drama de ser dois é um livro em que eu confesso o meu desconforto permanente com o mundo secular. Nesse poema eu me descrevia como uma espécie de pessoa entre dois mundos que eu não sabia definir. E ainda hoje acho que esse é um traço fundamental do meu perfil: eu não pertenço a nada. Não pertenço a instituições, não tenho fidelidade a coisas sociais; tudo o que é social, para mim é instrumento (RAMOS apud OLIVEIRA, 1995, p. I34).

Alberto Guerreiro Ramos foi sociólogo e político brasileiro, negro, baiano nascido em Santo Amaro no dia I3 de setembro de I9I5, e autodidata. Segundo Brito, Leite e Ferreira (20I6), há indícios de que seu pai, nascido livre, fora filho de ex-escravos, e de que sua mãe havia sido vendida pela família a traficantes de escravos de Angola. Partindo de seu próprio método perspectivista, como será exposto mais à frente, a situação da sua vida particular desde a infância e juventude são fatores importantes para entender a trajetória intelectual de Guerreiro. Como levantado por Brito, Leite e Ferreira em seu trabalho quantitativo sobre a produção da academia brasileira, é possível levantar a hipótese de os motivos de Guerreiro terem sido apagados das investigações de ciências humanas: "era errante", nas palavras de Maria Stella de Amorim durante o painel "Contribuição de Guerreiro Ramos para a sociologia brasileira", organizado pela Fundação Getúlio Vargas um ano após a sua morte (PRIMEIRO..., I983). Foi um ator político nacional e dentro da própria academia: no espaço de homens brancos, era firme e polêmico, com ideias contra-hegemônicas de estruturar um pensamento sociológico no Brasil e para o Brasil. 
O título da presente seção é o mesmo de seu livro de poemas publicado em I937, período em que consumia demasiadas obras existencialistas francesas. Apesar de escrito aos 22 anos, como apontado por Brito, Leite e Ferreira (20I6), explica profeticamente a trajetória do autor. No curto período entre a Lei Áurea e seu nascimento, são notáveis os impactos sentidos por Guerreiro. Ao longo de toda a sua jornada, há questionamentos próprios e de outros (como o da escola paulista de sociologia) sobre o que é Guerreiro Ramos - acadêmico, político, sociólogo, jornalista, ou simplesmente polêmico? O título da obra de Soares (2006) responde aos questionadores: A sociologia crítica de Guerreiro Ramos: um estudo sobre um sociólogo polêmico. Era polêmico, pois falava de modo firme, pensava a sociologia de forma política para o desenvolvimento nacional brasileiro e por estar no espaço de brancos. Teve ascensão por seu grande intelecto, sendo desde cedo professor particular da elite baiana e aprendendo a disciplina acadêmica por conta própria. Excepcional em seu tempo, graças a uma bolsa de estudos concedida pelo governo da Bahia foi estudar Ciências Sociais em 1939 na Faculdade Nacional de Filosofia do Rio de Janeiro, graduando-se na primeira turma da instituição em 1942 e bacharelando-se em Direito um ano depois pela mesma instituição. Ainda em I943, trabalhou como técnico administrativo do Departamento Administrativo do Serviço Público (Dasp). Suas análises sociológicas da realidade brasileira não foram deixadas de lado — durante toda a sua vida, manteve atuação burocrática e política enquanto produzia. Sobre isso, Nelson Mello e Souza ressaltou no mesmo painel, em 1983, que o tempo de Guerreiro sempre fora escasso, pois tinha seu engajamento político ativo, em simultâneo com sua produção acadêmica e intelectual. Entre 1949 e 1950, foi também integrante do Teatro Experimental do Negro, do Instituto Nacional do Negro e do Jornal do Quilombo, tendo extensa produção sociológica sobre o negro no Brasil.

O sociólogo visava - mediante a superação dos ressentimentos e dos recalques suscitados pelo preconceito racial e a alteração das atitudes e mentalidades negativas de brancos e negros referentes à cor — estimular a in-
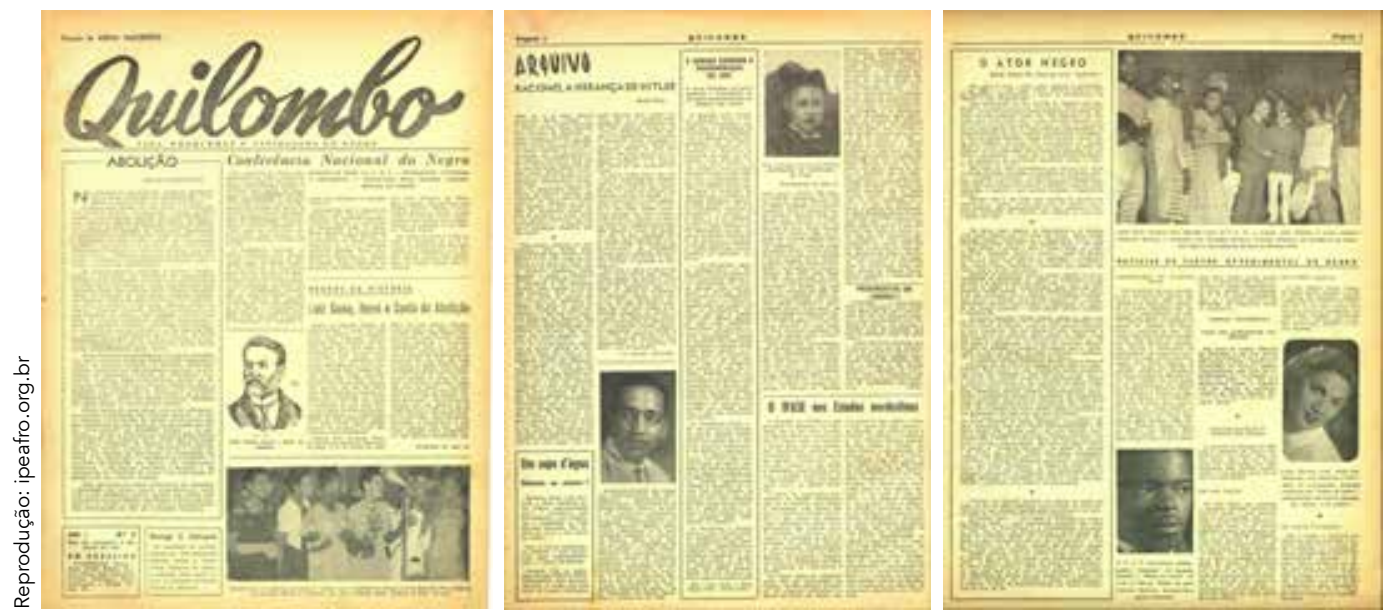

Páginas do jornal Quilombo (ano I, n² 2, maio de 1949), com o qual Guerreiro Ramos colaborou entre 1949 e 1950 
tegração efetiva da população negra à sociedade brasileira. Nesse sentido, Guerreiro também defendeu a implementação de políticas sociais, de educação e formação profissional que contribuíssem para a ascensão social do negro (MAIO, 2015, p. 606).

Segundo Simon Schwartzman, Guerreiro dialogava criticamente com os autores sobre questões raciais:

Para ele, havia duas tradições brasileiras no tratamento da questão do negro, uma totalmente perdida e negativa, outra recuperável. A melhor tradição era a que incluía Alberto Torres, Euclides da Cunha e Oliveira Vianna. Era verdade que Euclides da Cunha acreditava na determinação geográfica e ecológica da cultura, e Oliveira Vianna, autor de Raça e assimilação, se preocupava com o branqueamento da população brasileira. Eles possuíam, apesar disso, uma ideia de processo, de história, de transformação, e por isso tinham uma contribuição importante a ser recuperada. A pior tradição era representada pelos que tinham uma ideia estática e pessimista do brasileiro, visto como uma raça impura e condenada pela contaminação do sangue negro. Arthur Ramos e Gilberto Freyre são indicados como os principais representantes dessa concepção imobilista, que no máximo olhavam para o negro como objeto folclórico, a ser estudado como os entomólogos estudam os insetos. Costa Pinto, contemporâneo de Guerreiro Ramos, é apontado como representante dessa tradição mais negativa, e contra ele se volta boa parte dos ataques da Cartilha brasileira do aprendiz de sociólogo, texto incorporado mais tarde em Introdução crítica à sociologia brasileira. O que Guerreiro Ramos propõe em troca é uma sociologia do negro feita pelo próprio negro, a partir da assunção de sua condição racial, a partir de uma tomada de consciência de sua negritude (PRIMEIRO..., I983, p. 2I).

No final de sua vida, em I98I, afirmou que "o Brasil é o país mais racista do mundo" (OLIVEIRA, I995, p. I74). Guerreiro tinha consciência, assim, do impacto contemporâneo e póstumo de sua atuação e produção no ambiente branco nacional. $\mathrm{O}$ trabalho de Maio (20I5) sintetiza os racismos enfrentados nos planos intelectual, político e pessoal. Exilado em Los Angeles desde I966, devido à ditadura civil-militar no Brasil, lecionou na Universidade do Sul da Califórnia e faleceu de câncer em I982. Em um fórum on-line, seu filho relata uma ironia dessa época:

O velho Guerreiro nos deixou em 6 de abril 1982, no Hospital Cedars-Sinai, em Los Angeles. Recentemente, baralhando seus arquivos pessoais deixados a mim por minha mãe, eu li que seu óbito oficial no Consulado em Los Angeles o constata como "branco". A vida é estranha, não? (GUERREIRO RAMOS FILHO, 20I6) 
Seus direitos políticos foram cassados pelo ato institucional $\mathrm{n}^{\circ} \mathrm{I}$, de 9 de abril de 1964, enquanto era deputado federal suplente pelo estado da Guanabara, desde I963, pelo Partido Trabalhista Brasileiro (PTB), atuando na vaga de Leonel Brizola. Curiosamente, tanto a cassação quanto o alinhamento ao PTB tinham uma origem comum: foi convidado pelo Partido Comunista a visitar a URSS e a China em I96I. Na visão da ditadura civil-militar brasileira, a viagem já bastava para ele ser perseguido - com certeza, era comunista. Entretanto, teve grande desafeto pelos soviéticos e os chineses, que o chamaram de traidor e oportunista: escreveu várias críticas depois da viagem, e disse diretamente aos intelectuais chineses e soviéticos: "Vocês não entendem de Brasil!" (OLIVEIRA, I995, p. I50). Com isso, escreveu sua obra Mito e verdade da revolução brasileira em I963, como um manifesto do PTB da Guanabara para que o partido renunciasse à ideologia marxista-leninista (ABREU, 200I).

O envolvimento com a prática política brasileira, contudo, é anterior: assessorou Getúlio Vargas na Casa Civil durante seu segundo mandato, quando conheceu os também isebianos Rômulo Almeida e Ignácio Rangel, formulando o "grupo de Itatiaia" com outros pensadores. Em I953, surge o antecessor do Iseb (Instituto Superior de Estudos Brasileiros), o Instituto Brasileiro de Economia, Sociologia e Política (Ibesp), grupo privado que teve como resultado os cinco volumes de "Cadernos de Nosso Tempo". Enfim, é criado o Iseb, como parte do Ministério de Educação e Cultura do governo de João Café Filho, em I955 (ABREU, 200I), sendo Guerreiro Ramos diretor do Departamento de Sociologia. Os cursos extraordinários ministrados por Guerreiro no Iseb foram, em I957, "Estrutura da sociedade brasileira", "Significação do nacionalismo" e "Estrutura atual e perspectiva da sociedade brasileira", e em I958, "Problemas metodológicos de uma sociologia brasileira" (OLIVEIRA; ARAGÃO, 2020). Guerreiro entendia que

o Iseb destinava-se ao estudo das ciências sociais, da compreensão crítica da realidade brasileira e da elaboração do referencial teórico que permitisse o desenvolvimento nacional. O Iseb pretendia, assim, ser uma instância de processamento do pensamento brasileiro (BRITO; LEITE; FERREIRA, 20I6, p. 289).

Afasta-se do instituto em dezembro de 1958, por não concordar com o apoio do grupo à candidatura do marechal Henrique Lott à Presidência.

\section{NACIONAL-DESENVOLVIMENTISMO: O MÉTODO E O PLANO}

Em Cartilha brasileira do aprendiz de sociólogo, Guerreiro Ramos (I954, p. I70) sintetiza sua visão sobre a produção sociológica dizendo que "a essência de toda sociologia autêntica é, direta ou indiretamente, um propósito salvador e de reconstrução social”. Na entrevista de I98I cedida a Lúcia Lippi, afirma que Max Weber foi o teórico que mais o influenciou enquanto profissional da ciência social (OLIVEIRA, I995, p. I44). 


\section{Guerreiro Ramos foi um grande}

pensador do desenvolvimento

nacional, não restringindo seu

trabalho à produção da teoria e à

prática. Antes, dá um passo para trás:

apresenta um modelo metodológico

para pensar a sociologia brasileira,

compreender seus problemas

efetivamente, pensar e planejar

soluções e, por fim, colocá-las em

prática

Guerreiro Ramos foi um grande pensador do desenvolvimento nacional, não restringindo seu trabalho à produção da teoria e à prática. Antes, dá um passo para trás: apresenta um modelo metodológico para pensar a sociologia brasileira, compreender seus problemas efetivamente, pensar e planejar soluções e, por fim, colocá-las em prática. É importante frisar que a metodologia da redução sociológica de Guerreiro se caracteriza pelo caráter sistemático de sua produção, isto é, a metodologia, a produção teórica sobre o desenvolvimento e a prática política estão diretamente ligados.

Na sua principal obra, A redução sociológica, produzida enquanto ele exercia a função de diretor do Iseb - a primeira edição é publicada em I958 -, Guerreiro apresenta um método sociológico nacional. Renega a transplantação da sociologia estrangeira (mais precisamente, da Europa e Estados Unidos), prática que denomina como sociologia consular, e mostra que não é lógica na sociedade brasileira. No âmbito metodológico, tratando da réplica de modelos exatos, em um dos exemplos utiliza o caso da análise de consumo alimentar criada por técnicos europeus para a Sociedade das Nações. O modelo analisou perfeitamente o consumo da Europa. Contudo, quando utilizado para pensar o caso brasileiro, mostrou distorções que não explicavam a realidade de facto - isto é, as variáveis utilizadas, por mais que fossem de excelência para explicar modelos europeus, não eram válidas para uma sociedade com comportamentos, cultura e fase diferentes (GUERREIRO RAMOS, I996, p. 8I83). O esforço da sociologia nacional deveria ser empregado para se entender a realidade nacional e adaptar os modelos externos para problemas reais do Brasil, e não apenas os transpor. Sobre isso, há também o esforço, que Guerreiro chama de "lucidez do pesquisador", em reduzir as variáveis secundárias para analisar um problema 
coletivo e real, e não um idealizado com base na percepção individual - o que pode ocorrer com a transplantação da sociologia estrangeira para fazer "análises de caso" sobre a situação nacional. Por exemplo, Guerreiro traz a questão do "controle social", que tinha extenso debate nos EUA, mas que não era um problema brasileiro. Afirma que se pode fazer uma análise da problemática no caso do Brasil, mas esse não era um aspecto da consciência coletiva da população, não era uma questão imanente - era apenas a transplantação do saber estrangeiro para o Brasil, distorcendo a realidade para se enquadrá-la nos moldes de uma problemática irreal da sociedade brasileira. Hoje se comete esse equívoco frequentemente, quando se tenta usar as mesmas categorias de análise do problema racial nos EUA e no Brasil sem fazer uma reflexão sobre até que ponto seriam válidas para realidades tão distintas.

Assim, Guerreiro Ramos propõe um trabalho inovador, de caráter anticolonial. No capítulo "Definição e descrição da redução sociológica" da supracitada obra, o autor explica o método em sete pontos:

I) é dotado de ação metódica, que afasta os elementos que dificultam a real percepção do objeto, analisando os aspectos diretos dos dados sem aceitá-los passivamente;

2) compreende a realidade social de forma sistemática, entendendo a relação do sentido dado ao objeto de estudo pelos valores e significações atribuídos pela vida humana;

3) assimila a noção de mundo, meditando sobre a relação entre consciência e objeto: "Toda consciência é intencional porque estruturalmente se refere a objetos. Todo objeto, enquanto conhecido, necessariamente está referido à consciência." (GUERREIRO RAMOS, 1996, p. 72);

4) tem caráter perspectivista, entendendo o sentido a partir do contexto aqui são notórias as influências existencialistas do autor;

5) é suportado pelo coletivo, pois se pensa a sociologia como um instrumento operativo da realidade, tendo-se de observar a lógica material imanente à sociedade para produzir esse saber;

6) deve ser crítico-assimilativo em relação à experiência estrangeira, dirigido por uma aspiração ao universal mediatizado pelo local, regional ou nacional;

7) por fim, apesar de o suporte coletivo ser a vivência popular, a redução sociológica é altamente elaborada, tendo sua validade científica confirmada pela justificativa e pela demonstração, de forma interdisciplinar e histórica.

Em suma, a redução sociológica é um exercício analítico e prático, com profundidade política e no sentido do desenvolvimento nacional. Nessa direção, Soares assegura que

Guerreiro parte da crítica do ideal da sociologia universal. "O ideal dos sociólogos é a sociologia 'universal', isto é, uma sociologia histórica e sobretudo nacionalmente descomprometida, uma sociologia tanto quanto possível aproximada, quanto ao grau de abstração, da física ou da matemática." Para 
ele, nem a física nem a matemática se eximem da contingência histórica, observando-se em ambas seu impacto não só na estrutura teórica como também na problemática dessas ciências (SOARES, 2006, p. 36).

Tendo em vista a crítica feita por Guerreiro em seu método, sobre a responsabilidade histórica da sociologia, é necessário avaliar o cenário em que o autor está inserido quando no Iseb. No contexto do pós-guerra a discussão era sobre a modernização das sociedades periféricas, e como elas se desenvolvem. Não à toa, havia diálogo com Celso Furtado e Raúl Prebisch, e coerência na produção de isebianos e cepalinos:

No pensamento do Iseb havia um conceito de desenvolvimento que tomava emprestadas ideias de Marx, de Schumpeter e do estruturalismo latino-americano de Raúl Prebisch e Celso Furtado, sem, entretanto, se preocupar em ser fiel a qualquer uma dessas visões. O desenvolvimento é um processo de acumulação de capital e de incorporação de progresso técnico por meio do qual a renda por habitante ou, mais precisamente, os padrões de vida da população aumentam de forma sustentada. Para o Iseb, assim como para a Cepal, desenvolvimento era industrialização, mas, mais do que isso, era o processo mediante o qual o país realizava sua revolução capitalista (BRESSER-PEREIRA, 2004, p. 55).

Diante desse debate, Guerreiro pensa o progresso na lógica do racionalismo moderno - isso explica a relação próxima do autor com a Administração na academia brasileira, já que via a sociologia como instrumento para a organização da sociedade. Justamente, ao pensar a periferia mundial, segundo Soares (2006, p. I84), afirma que seu "desenvolvimento implicava a crítica da dominação política (colonialismo), particularmente sob o aspecto cultural, a crítica da dominação econômica ('imperialismo') e a ênfase no papel da industrialização, considerando também os aspectos sociais e políticos desta".

Emana, então, o pensar sociológico do Iseb pelo nacional-desenvolvimentismo. Nesse caminho, Hélio Jaguaribe, no painel "Guerreiro Ramos e o desenvolvimento brasileiro", diz que a preocupação do instituto era refletir sobre a metodologia do desenvolvimento, superando as escolas clássicas (tanto o positivismo quanto o marxismo). Ainda em A redução sociológica, Guerreiro Ramos discorre sobre a organização do desenvolvimento em fases (sendo o conceito classificatório, não como empírico). Define fase como uma totalidade histórico-social construída por atores em relação dialética. Por isso, alega que os problemas sociais são dados pela fase vigente. De forma clara, é parte da crítica metodológica do autor à transposição de problemas estrangeiros, irreais na sociedade nacional - cada sociedade está em uma fase distinta, com atores e relações dialéticas próprios. $\mathrm{E}$ as questões da sociedade brasileira no contexto pós-guerra, pós-suicídio de Getúlio, ascensão da Cepal, no período de industrialização de Juscelino Kubitschek (JK), em que os intelectuais se debruçavam sobre os caminhos do desenvolvimento periférico, eram fruto da simultaneidade de 


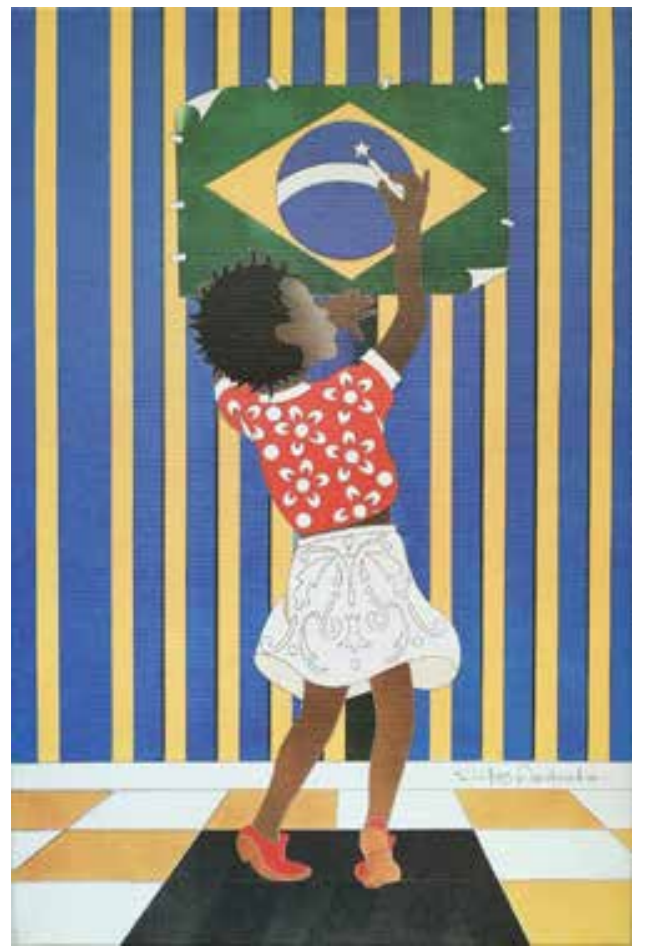

Menina com bandeira

do Brasil, gravura de

Elifas Andreatto

fases. O latifúndio continuará forte mesmo com a chegada da fase de industrialização. Justamente essa era a dificuldade do estabelecimento de uma burguesia nacional comprometida com o desenvolvimento - seu papel era dependente da fase latifundiária. Em ambiente macro, Guerreiro também apontava como falha a ausência de responsabilidade burguesa devido ao período histórico da industrialização dos países periféricos, muito posterior à dos países centrais, o que limitava sua capacidade de penetração no mercado - a burguesia industrial brasileira, tímida demais, não tinha consciência da sua obrigação de assumir a direção do processo desenvolvimentista.

A consciência coletiva das transformações em curso, portanto, vinha de outra classe. Os dirigentes do desenvolvimento nacional eram os trabalhadores e a classe média, que viviam os fatores que originaram a consciência crítica: a industrialização, a urbanização e a alteração do consumo. Isto é, tendo a classe média assimilado novos hábitos, não passivos, sua noção política sobre o processo de desenvolvimento pressiona para que cada vez mais seus acessos sejam aprimorados e expandidos. Doravante, Guerreiro Ramos exalta a importância de o desenvolvimento ser nacional, e não replicado do estrangeiro - a população brasileira tem caráter crítico e ativo, assim deve-se pensar o desenvolvimento segundo a redução sociológica. Pontua essa fase a relação dialética entre latifúndio, burguesia industrial e classe trabalhadora (a dualidade da sociedade brasileira) — há o tensionamento entre os moldes capitalistas antigos e os novos, entre o pensar colonial e a mentalidade nacional autêntica.

Finalmente, o sentido do desenvolvimento nacional brasileiro é visto por Guerreiro Ramos, nacionalista, referido à população, garantindo a vida e a erradicação da miséria e suas consequências. O desenvolvimento nacionalista objetiva a au- 
tonomia do Estado. Como abordado anteriormente por Bresser-Pereira, o desenvolvimento, para Guerreiro, deve ter caráter anticolonial (crítica política ao colonialismo e econômica ao imperialismo) e ser instrumento de inclusão social, em que todos os excluídos não sejam meros objetos sociológicos ou "mão de obra barata nos processos de produção, mas sim sujeitos de direitos no desenvolvimento das políticas públicas" (NOGUEIRA, 2006, p. 70). Logicamente, tal desenvolvimento deveria ser nacionalista - o nacionalismo segundo Guerreiro Ramos é a luta da periferia pela sua soberania plena e libertação do colonialismo. No Brasil de Guerreiro, é o movimento popular emancipatório guiado para o universalismo (soberania plena).

Conclusivamente, a proposta de nacional-desenvolvimentismo de Guerreiro Ramos é indissociável de sua metodologia. $\mathrm{O}$ autor trabalha com a epistemologia política dos intelectuais, elaborando uma sociologia nacional feita no Brasil e para o Brasil, esmiuçando os reais problemas do desenvolvimento periférico brasileiro. Como resultado dos estudos de autores existencialistas e fenomenológicos, a sociologia de Guerreiro é ferramenta aplicada, engajada e ativa para a ação política.

\section{DIREÇÃO DE GUERREIRO NO DEPARTAMENTO DE SOCIOLOGIA DO ISEB}

A aula inaugural de Guerreiro Ramos como diretor do Departamento de Sociologia do Iseb em I957 é nomeada "Condições sociais do poder nacional", discorrendo sobre o método e a análise sociológica. Parte do poder weberiano de imposição provável da vontade numa relação social para falar da vontade, que, segundo Guerreiro, é apta à coerção enquanto garante as possibilidades da fase vigente, legitimada pelos valores da consciência e ação coletiva. Assim, define como poder nacional os dirigentes ativos na organização nacional, dotados de elementos políticos para a direção do desenvolvimento do país (SOARES, 2006).

A classe dirigente, para Guerreiro, não é a classe dominante marxista. Ilustração clara disso é o Brasil — após a independência não havia condições socioeconômicas para o estabelecimento do poder nacional. O que os proprietários de terra fizeram nessa fase inicial foi meramente organizar a administração local, com fins de complementariedade da Europa. Não havia compromisso com o desenvolvimento nem condições para estabelecê-lo — não havia consciência crítica subjetiva da classe dirigente. Soares (2006, p. I59) elucida o raciocínio ressaltando que "a classe dominante não se tornara classe dirigente na medida em que não possuía consciência das necessidades orgânicas da sociedade”.

Como alternativa única para a posição colonial do Brasil independente, tem-se a práxis coletiva, tendo como objetivo a soberania efetiva. Essa ação popular é o que fundamenta o nacionalismo de Guerreiro Ramos, ou, em outras palavras, o projeto de apropriação coletiva de si.

Com base nessa análise é que Guerreiro aponta o Brasil como inesgotável para os trabalhos das ciências sociais, pois o desenvolvimento brasileiro deve ser pensado desde sua ontologia, da análise histórica e do perspectivismo de valores. A 
grandiosidade de Guerreiro Ramos está na totalidade de sua obra, em dialogar com o método, a teoria e a ação, todas conectadas pela lógica dialética. Assim, há a defesa da planificação social, que Guerreiro define como a investigação sociológica do sistema de forças sociais e a invenção de instituições para o funcionamento da estrutura social (SOARES, 2006).

Já nessa primeira aula de Guerreiro no Iseb, é possível compreender a abordagem sociológica do instituto, que estava interessado em acelerar o desenvolvimento brasileiro. Liderado por Hélio Jaguaribe, constituía uma escola de intelectuais (não necessariamente acadêmicos, o que foi alvo de crítica da escola paulista) que pensavam sobre o desenvolvimento nacionalista brasileiro, sendo aparato de Estado de Juscelino Kubitschek. Apesar dos esforços de Guerreiro na ação política como burocrata, o Iseb era um ambiente de pensamento e não de ação factual (BRESSER-PEREIRA, 2004). Contudo, o instituto não foi responsável pela formulação do desenvolvimento nacional de JK, apesar de exercer certa influência nela: o Plano de Metas tinha como condição a cooperação internacional para a superação do subdesenvolvimento, enquanto Guerreiro defendia a redução do capital estrangeiro no Brasil, para reduzir suas consequências expropriadoras e impedir o direcionamento da nação por agentes externos. Ao passo que JK utilizava a entrada de investimentos externos no Brasil para a superação do subdesenvolvimento, obtendo sucesso em sua empreitada, o Iseb foi impactado por uma crise interna de compreensão da nova lógica não nacionalista em I958, quando Hélio Jaguaribe e Guerreiro Ramos se retiram do instituto (TERCEIRO..., I983).

De fato, as críticas de Guerreiro às ciências sociais como instrumento político da prática podem ser aplicadas à situação do Iseb — a falta de articulação deste com a vida pública no período de Juscelino prejudicou a aplicação do desenvolvimentismo nacionalista. $\mathrm{O}$ instituto ter atuado como espaço de ideias e não de prática afastou a aplicação de seu pensamento do plano de desenvolvimento do país, conduzindo à decadência das atividades nesse tempo. Guerreiro compreendia a situação de forma crítica, pois responsabilizava as decisões políticas e institucionais pelo atraso tecnológico. Nas palavras de Soares (2006, p. I88), "afirmava ainda que a capacidade política dos governantes gera a capacidade tecnológica em suas respectivas nações".

Dessa maneira, o desenvolvimento trabalhado por Guerreiro Ramos, Hélio Jaguaribe e Ignácio Rangel é "conceito histórico de revolução capitalista, por meio da industrialização e de revolução nacional, que torna o país capaz de tomar suas decisões essencialmente em função dos interesses nacionais" (BRESSER-PEREIRA, 2004, p. 75). Para isso, as análises sociológicas de Guerreiro sobre a classe dirigente e a consciência crítica coletiva eram fundamentais para os autores do Iseb pensarem no sujeito norteador do desenvolvimento nacionalista brasileiro. Como visto anteriormente, Guerreiro via a classe trabalhadora como a classe dirigente de forma nítida na fase dos anos I950, entretanto, os isebianos estavam em comum acordo sobre a necessidade de a burguesia nacional industrial liderar o processo de desenvolvimento da sociedade brasileira. Guerreiro Ramos entendia que tal necessidade implicava 


\section{Desenvolvimento, segundo Guerreiro}

\section{Ramos, é estabelecer condições}

\section{políticas e institucionais para dirigir}

o Brasil à soberania efetiva, ao

desenvolvimento nacional e autônomo, renegando as amarras coloniais

romper com o caráter colonial de complementariedade do Brasil à Europa e estabelecer a soberania efetiva, mas o autor não via possibilidades tangíveis de a burguesia industrial brasileira assumir essa responsabilidade - era classe dominante, não dirigente. Ainda era destituída de consciência coletiva, subjetividade e objetivo de desenvolvimento.

Justamente para tornar a burguesia industrial brasileira em classe dirigente, Guerreiro Ramos defendia o Iseb atuante com ela, e com a classe trabalhadora e estudantil, para pressionar politicamente o direcionamento do país - raciocínio que suscitava grande discórdia no instituto, principalmente da parte de Hélio Jaguaribe,

que defendia que o Iseb deveria atuar como agência de cultura, preocupado com a elaboração de estudos sobre a realidade brasileira, e que o órgão deveria ser um dos centros formadores das elites dirigentes do país. Recusava o envolvimento do órgão na luta política partidária (TERCEIRO..., I983, p. 7I).

Por essas razões, desenvolvimento, segundo Guerreiro Ramos, é estabelecer condições políticas e institucionais para dirigir o Brasil à soberania efetiva, ao desenvolvimento nacional e autônomo, renegando as amarras coloniais. Isso era o que Guerreiro defendia e produzia no Iseb, além de sua atuação política e burocrática na vida pública, seguindo sua atitude metódica. Estabelecidas as condições para o desenvolvimento, então era possível o direcionamento para o desenvolvimento sem distorções, pois a compreensão profunda da realidade nacional fundamentaria a plenitude das decisões políticas e institucionais - a redução sociológica na práxis.

A posição da sociologia de Guerreiro no Iseb é disruptiva com a sociologia predominante, tanto em ambiente nacional quanto internacional. No Brasil, a disciplina estabelecia-se enquanto saber científico nos termos de Durkheim. Isto é, distante do pesquisador, imparcial, um saber neutro, a verdadeira e legítima ciência. Guerreiro Ramos surge como um catalisador de tudo o que é condenável por essas premissas. Para ele, a sociologia é uma ciência datada, é um instrumento para entender a realidade presente e uma atitude metódica política para solucionar os problemas sociais existentes. Defendia o saber sociológico para além dos muros da universidade e se aproximava intensamente dos seus objetos. 

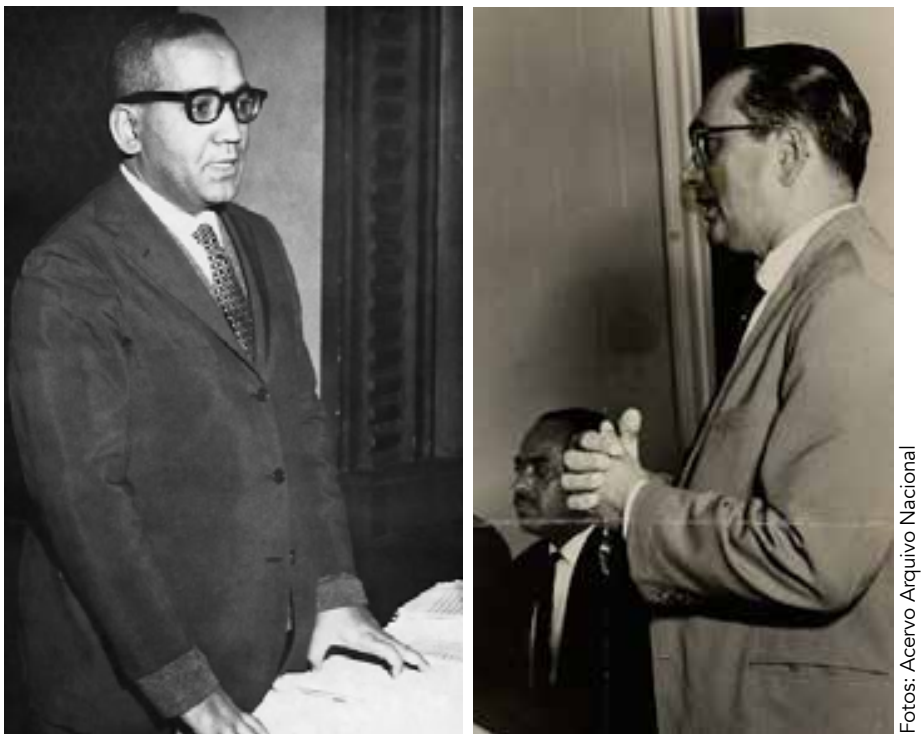

Guerreiro Ramos (esq.)

e Florestan Fernandes:

olhares divergentes sobre o

desenvolvimento nacional

\section{CARIOCAS E PAULISTAS: ISEB NA SOCIOLOGIA NACIONAL}

\section{Dado o distanciamento} histórico e temporal, é notável que os esforços da redução sociológica de Guerreiro tenham sido vencidos. O embate existiu com a escola paulista, sob a direção de Florestan Fernandes. Guerreiro Ramos, de forma enfática e polêmica, acusava os paulistas de não terem comprometimento com a realidade social brasileira. As motivações dessa acusação residiam no imperativo anticolonialista de Guerreiro, enquanto a Florestan pouco importavam as noções de soberania efetiva. Para os paulistas, a sociologia brasileira deveria ser estabelecida segundo a lógica da modernidade, e não rompendo com ela; ter a excelência científica era prioridade em detrimento da ação política imediata (BARIANI, 2006). Retirando os elementos secundários da discussão (o estabelecimento da disciplina sociológica brasileira), a pauta entre os dois atores era, na verdade, o desenvolvimento nacional. Aos olhos de Guerreiro, a sociologia deveria visar ao nacionalismo, desenvolvimento e autonomia; Florestan pretendia ater-se ao universalismo, inserido na lógica importada de generalização e intensificação da sociedade competitiva dotada das possibilidades da modernidade. Em suma,

a disputa não envolvia apenas dois sociólogos em franca ascensão intelectual, nem dois scholars, mas distintas formas de institucionalização das ciências sociais (em São Paulo e no Rio de Janeiro), de socialização e formação intelectual — teórica, política e ideológica —, de concepção da sociologia e do papel do sociólogo; diferentes interpretações da sociedade brasileira, "visões de mundo", projetos para as ciências sociais e, no limite, para o Brasil (BARIANI, 2006, p. I5I).

Florestan entendia a sociologia como instrumento técnico da lógica vigente; Guerreiro, como atitude metódica para o desenvolvimento nacional. Florestan, portanto, ao guerrear contra Guerreiro, estava buscando o desenvolvimento brasileiro por via da fase do capitalismo em que o país se encontrava, sem propor um direcionamento para além da estrutura híbrida colonial de complementação à Europa, sem rompimentos estruturais - tanto que utilizava a sociologia para pensar particularidades, e não o todo. O transplante de modelos analíticos europeus era cabível para investigar a so- 
ciedade brasileira. Portanto, não há responsabilidade nacional na sociologia da Escola Paulista, alegava Guerreiro. Listando as diferenças epistemológicas dos autores, tem-se:

I) Florestan Fernandes aceitaria a sociologia como ciência positiva do social (Weber, Durkheim e Marx são seus modelos); Guerreiro Ramos, mais cético, teria raízes filosóficas (no existencialismo e culturalismo), mas aceitaria a sociologia como ciência empírico-indutiva;

2) a relação entre sujeito e objeto do conhecimento e o caráter desse conhecimento seriam tomados de modos diferentes por ambos: Florestan ligar-se-ia à herança dos clássicos (Marx, Weber, Durkheim), e Guerreiro seguiria a linha de Gurvitch - e partilharia a herança de Proudhon e Saint-Simon;

3) para Florestan ciência seria positividade, para Guerreiro, perspectiva;

4) no entender de Florestan a ciência seria feita na academia por acadêmicos; Guerreiro Ramos discordaria;

5) finalmente, para Florestan — que desenvolveria um padrão mais positivo de sociologia - os "fatores endógenos do conhecimento são mais importantes, universais e passíveis de serem transplantados dos centros mais desenvolvidos para as condições brasileiras"; já Guerreiro seguiria um padrão mais normativo de ciência - "pelo qual o dever ser pode agir sobre a consciência e sobre a realidade" e "os fatores exógenos do conhecimento estão presentes em todas as etapas da produção do saber sociológico” (BARIANI, 2006, p. I56).

A nação era primordial para Guerreiro, e a ciência social, uma decorrência desta para sua transformação, enquanto Florestan tinha as obrigações científicas como superiores, para que finalmente pudessem ser úteis ao desenvolvimento nacional.

À luz da redução sociológica, a articulação de Florestan e da escola paulista era marca do tempo contextualizado e perspectivista da metateoria da sociologia brasileira. No contexto da década de 1950, do período de Juscelino, era o desenvolvimento pela cooperação nacional que estava em curso, assim como a ausência de consciência da elite nacional sobre sua posição enquanto dirigente do desenvolvimento brasileiro. $\mathrm{O}$ sucesso da sociologia de Florestan era parte do Estado planificador, que buscava alterações controladas. A sociologia da Escola Paulista cumpria muito bem o papel de servidão tecnocrática das burocracias desse Estado. Por isso, Lúcia Lippi Oliveira conclui, em I983, que a sociologia de mangas de camisa (a de Guerreiro) foi arquivada pela academia brasileira: "estava por demais comprometida com as circunstâncias históricas" (PRIMEIRO..., I983, p. 20).

Guerreiro perdeu o embate do período, e a posição da escola paulista foi adotada para direcionar o saber sociológico nas instituições nacionais. Contudo, a tendência é de a atitude metódica de Guerreiro ser cada vez mais retomada, partindo das instituições periféricas nacionais - a geopolítica do conhecimento e a desconstrução das humanidades positivistas estão, vagarosamente, tomando o lugar da sociologia de Florestan. A fase atual brasileira demanda comprometimento e responsabilidade histórica dos produtores de ciência social no Brasil. 


\section{CONSIDERACÕ̃ES FINAIS: A ATUALIDADE DE GUERREIRO RAMOS}

O Brasil passa por um momento histórico dramático em 202I, com um desgoverno, uma crise social e econômica, resultado da covid-I9, e assassinatos recorrentes de negros pelo aparato policial oficial, denotando uma sociedade evidentemente violenta e racista. Não é mera coincidência esse conjunto de problemas sociais, e ele justifica um momento de muito pessimismo no país. Talvez, retomando os exemplos biográficos, metodológicos e políticos de Guerreiro Ramos, possamos diagnosticar como chegamos a esse caos no país e propor alternativas. Nesse sentido estamos de acordo com Hélio Jaguaribe sobre Guerreiro:

É isso que me parece que existe no pensamento e na obra dele: a consciência de que para romper as formas remanescentes da oligarquia rural, do mercantilismo e de uma série de outros elementos estagnadores da sociedade brasileira era necessário não apenas contar com a burguesia nacional, como muito foi dito, mas, além disso, mobilizar um movimento popular de base. Entretanto, era preciso que essa mobilização popular de bases evitasse os riscos de cair num partido único, num mobilizacionismo de tipo massificante e excludente das liberdades, em vez de numa verdadeira democracia (TERCEIRO..., I983, p. 90).

Infelizmente o Brasil se encontra muito distante dessas propostas de Guerreiro Ramos, mas é justamente agora, quando o país se encontra sem projeto, sem liderança e não encara de forma sincera e frontal seus problemas estruturais seculares, o momento adequado para a revalorização do pensamento, do engajamento e de propostas emancipadoras. É hora de reconstruirmos um projeto de país, e Guerreiro Ramos pode ser uma inspiração valiosa para este momento.

* Professor adjunto da Universidade Federal da Integração Latino-Americana (Unila). Coordenador do Grupo de Pesquisa Descolonizando as Relações Internacionais e do Projeto de Extensão Observatório dos Brics e das Relações Sul-Sul. Suas principais linhas de pesquisa no momento são: economia política internacional, geopolítica da Amazônia, Brics e Relações Sul-Sul. E-mail: borges_fabio@yahoo.com.br

** Graduanda em Relações Internacionais e Integração. Pesquisadora e extensionista do Observatório dos Brics e das Relações Sul-Sul e do Grupo de Pesquisa Descolonizando as Relações Internacionais da Unila, do Centro de Estudos Asiáticos da Universidade Federal Fluminense (UFF) e do Grupo de Estudos sobre Brics da Universidade de São Paulo (USP). Desenvolve pesquisas em desenvolvimento, relações Sul-Sul, Brics e infraestrutura chinesa na América Latina. E-mail: luizammart@gmail.com

Texto recebido em 2 de junho de 2021; aprovado em 7 de julho de 2021. 
ABREU, Alzira Alves de. Alberto Guerreiro Ramos. In: ABREU, Alzira Alves de. Dicionário histórico biográfico brasileiro pós-1930. Rio de Janeiro: FGV Editora, 2001. p. 111-112.

BARIANI, Edison. Padrão e salvação: o debate Florestan Fernandes x Guerreiro Ramos. Cronos, v. 7, n. 1, 2006. Disponível em: <https://periodicos.ufrn.br/cronos/article/view/3194>. Acesso em: 10 maio 2021.

BRESSER-PEREIRA, Luiz Carlos. O conceito de desenvolvimento do Iseb rediscutido. Dados, Rio de Janeiro, v. 47, n. 1, p. 49-84, 2004. Disponível em: <https://doi.org/10.1590/S0011$52582004000100002>$. Acesso em: 21 maio 2021.

BRITO, Evandro Oliveira de; LEITE, Ilka Boaventura; FERREIRA, Luiza Brandes de Azevedo. Uma trajetória transdisciplinar: nota biobibliográfica. Ilha Revista de Antropologia, Florianópolis, v. 18, n. 1, p. 279-310, 19 jun. 2016. Disponível em: <http://dx.doi.org/10.5007/2175-8034.2016v18n1p269>. Acesso em: 21 jun. 2021.

GUERREIRO RAMOS, Alberto. A redução sociológica. Rio de Janeiro: Editora UFRJ, 1996.

Cartilha brasileira do aprendiz de sociólogo: prefácio a uma sociologia nacional. Rio de Janeiro: Andes, 1954.

GUERREIRO RAMOS FILHO, Alberto. Biografia de Alberto Guerreiro Ramos. Jus, 2016. Disponível em: <https://jus.com.br/duvidas/21685/biografia-de-alberto-guerreiro-ramos>. Acesso em: 22 maio 2021.

MAIO, Marcos Chor. Cor, intelectuais e nação na sociologia de Guerreiro Ramos. Cadernos Ebape. br, Rio de Janeiro, v. 13, p. 605-630, set. 2015. Disponível em: <www.scielo.br/scielo.php?script=sci_ arttext\&pid=S1679-39512015000700007\&lng=en\&nrm=iso>. Acesso em: 19 maio 2021.

NOGUEIRA, João Carlos. A sociologia e a política em Guerreiro Ramos. Esboços, Florianópolis, v. 13, n. 15, p. 67-84, jan. 2006. Disponível em: <https://periodicos.ufsc.br/index.php/esbocos/article/ view/235>. Acesso em: 21 maio 2021.

OLIVEIRA, Lúcia Lippi. A sociologia do guerreiro. Rio de Janeiro: Editora da UFRJ, 1995.

Guerreiro ontem, Guerreiro hoje. Revista de Administração Pública, Rio de Janeiro, v. 31, n. 5, p. 9-14 set.-out. 1997. Disponível em: <www.usfx.bo/nueva/vicerrectorado/citas/SOCIALES_8/ Sociologia/95.pdf>. Acesso em: 21 maio 2021.

OLIVEIRA, Maria Teresa Cavalcanti de; ARAGÃO, Luciano Ximenes. Iseb — Instituto Superior de Estudos Brasileiros: a ação do MEC na formação acadêmica de intelectuais orgânicos do "nacionaldesenvolvimentismo" nos anos 1950. Revista Histedbr On-Line, Campinas, v. 20, n. 30, p. 1-22, 30 abr. 2020. Disponível em: <https://periodicos.sbu.unicamp.br/ojs/index.php/histedbr/article/ view/8654062/22300>. Acesso em: 21 maio 2021.

PRIMEIRO painel: contribuição de Guerreiro Ramos para a sociologia brasileira. Revista de Administração Pública, v. 17, n. 2, p. 9-34, 18 set. 1983. Disponível em: <http://bibliotecadigital.fgv. br/ojs/index.php/rap/article/view/10942>. Acesso: 21 maio 2021.

RIBEIRO, Darcy. O povo brasileiro. São Paulo: Global, 2014.

SOARES, Luiz Antônio Alves. A sociologia crítica de Guerreiro Ramos: um estudo sobre um sociólogo polêmico. Rio de Janeiro: CRA-RJ, 2006.

SOUZA, Gustavo Costa de; MENDONÇA, Izadora Pereira. A contribuição de Alberto Guerreiro Ramos para a descolonização das ciências sociais no Brasil. Anais Eletrônicos do Congresso Epistemologias do Sul, v. 2, n. 1, p. 36-43, 2018. Disponível em: <https://revistas.unila.edu.br/aeces/article/view/837>. Acesso: 12 maio 2021.

TERCEIRO painel: Guerreiro Ramos e o desenvolvimento brasileiro. Revista de Administração Pública, v. 17, n. 2, p. 63-92, 18 set. 1983. Disponível em: <http://bibliotecadigital.fgv.br/ojs/index. php/rap/article/view/11128>. Acesso: 21 maio 2021. 